\title{
Aiura, A NEW GENUS OF CAMPOPLEGINAE (HYMENOPTERA; ICHNEUMONIDAE) FROM BRAZIL
}

\author{
ONODY, H. C. ${ }^{1}$ and PENTEADO-DIAS, A. M. ${ }^{2}$ \\ ${ }^{1}$ Programa de Pós-graduação em Ecologia e Recursos Naturais, Universidade Federal de São Carlos, \\ Rodovia Washington Luís, Km 235, C. P. 676, CEP 13565-905, São Carlos, SP, Brazil \\ ${ }^{2}$ Departamento de Ecologia e Biologia Evolutiva, Universidade Federal de São Carlos, \\ Rodovia Washington Luís, Km 235, C. P. 676, CEP 13565-905, São Carlos, SP, Brazil \\ Correspondence to: Angélica Maria Penteado-Dias, Departamento de Ecologia e Biologia Evolutiva, \\ Universidade Federal de São Carlos, Rodovia Washington Luís, Km 235, C. P. 676, CEP 13565-905, \\ São Carlos, SP, Brazil, e-mail: angelica@ power.ufscar.br \\ Received December 10, 2004 - Accepted January 3, 2005 - Distributed May 31, 2006 \\ (With 6 figures)
}

\begin{abstract}
Aiura, a new genus of Campopleginae (Hymenoptera; Ichneumonidae) and the species A. miri and A. turu are described from Campos do Jordão, SP, Brazil.
\end{abstract}

Keywords: Campopleginae, Ichneumonidae, Aiura n. gen., taxonomy, Atlantic Forest.

\section{RESUMO}

\section{Aiura, um novo Gênero de Campopleginae (Hymenoptera; Ichneumonidae) do Brasil}

Aiura, um novo gênero de Campopleginae (Hymenoptera; Ichneumonidae) e duas novas espécies A. miri e A. turu de Campos do Jordão, SP, Brasil são descritos.

Palavras-chave: Campopleginae, Ichneumonidae, Aiura n. gen., taxonomia, Mata Atlântica.

\section{INTRODUCTION}

Campopleginae is a large subfamily of Ichneumonidae with about 20 genera in the Neotropical region, 17 of which occur in Brazil (Townes \& Townes, 1966; DeSantis, 1980; Kumagai \& Graf, 2000).

Amongst material collected during the project "Diversity of Braconidae (Hymenoptera) fauna at different altitudes in Campos do Jordão, São Paulo, Brazil" eight specimens were found, which are called Aiura, a new genus.

The specimens were collected in the Atlantic forest $\left(22^{\circ} 44^{\prime} \mathrm{S}\right.$ and $\left.45^{\circ} 30^{\prime} \mathrm{W}\right)$ at high altitudes, occurring above $1100 \mathrm{~m}$.

Aiura runs to couplet 41 in Townes key (1970) for the Campopleginae genera. It is, however, different from Tranosema Foerster, 1869 and Diadegma Foerster, 1869 by having mesopleurum coriaceous; propodeum long, posteriorly produced into a "neck"; metasoma strongly compressed and elongated; tergite II long, thyridium separated from the base by about 4.0-5.0 times its length; tergites III and the following ones posteriorly incised mid-dorsally; ovipositor very stout, compressed laterally and up curved.

The terminology in this study follows Townes (1969, 1970). The type of material is deposited in the DCBU collection (Departamento de Ecologia e Biologia Evolutiva, UFSCar, São Carlos, SP, Brazil).

\section{Aiura n. gen.}

Type species: Aiura turu n. sp., present designation.

Description: Small to medium sized campoplegines, body slender. Eyes moderately indented opposite antennal sockets (Fig. 3). Cheek moderately long. Clypeus weakly convex to flat, its apex subtruncate. Mandible of moderate length, its 
lower margin with a flange, gradually narrowed to the midlength of mandible; teeth about same length. Temple moderately long. Genal carina joining oral carina. Posterior mesosternal carina complete. Propodeum in profile long, produced into a "neck" (Fig. 4); propodeal spiracle circular-subcircular. Propodeal carina present or obsolescent; areola confluent with petiolar area. Hind basitarsus without a distinct medium ventral row of closely spaced small hairs. Fore wing 3.5-5.0 mm, areolet present, petiolate above and receiving second recurrent vein distad of the middle. Nervullus distad of basal vein about 0.2 its length. Hind wing with nervellus not intercepted, slightly reclivous. Metasoma very long and slender; first segment with suture between tergite and sternite ventral and glymma present (Fig. 5); thyridium subcircular and very distant from base of tergite II (Fig. 6); tergites III and the ensuing posteriorly incised mid-dorsally (Fig. 2). Ovipositor stout, strongly up curved and longer than apical depth of abdomen.

Etymology: The genus name derives from the Tupy language (Aiúra = "neck"), with reference to the shape of the propodeum produced into a "neck".

\section{Aiura turu n. sp.}

Female: Fore wing length $5.0 \mathrm{~mm}$. Head with interocellar distance about 1.3 times orbitalocelar distance; mandible moderately long, with a lamella gradually narrowed and teeth about same length; temple moderately long; eyes moderately indented opposite antennal sockets; cheek about 0.75-0.80 basal mandibular width; antenna with 33 flagellomeres.

Mesoscutum uniformily coriaceous, without notaulices; propleura anteriorly rugose, posteriorly coriaceous; mesopleuron coriaceous, in front of speculum slightly rugose, lower part of mesopleuron without sternaulus impressed; posterior mesosternal carina complete; scutellum weakly convex, without carinae; metapleuron coriaceous. Propodeum (Fig. 1) bearing long and dense pubescence, especially in the middle and laterally, anteriorly coriaceous, centrally and posteriorly rugose; spiracle propodeal circular; areola short, confluent with petiolar area.

First segment with suture between tergite and sternite ventral, deep glymma in front of spiracle; second tergite long with subcircular thyridium separated from base of tergite by about 5 times its length. Ovipositor stout, strongly up curved, about 2 times as long as apical depth of abdomen.

Black; mouthparts yellow; scape yellow, dorsally black; pedicel almost entirely black, with yellow spot; antennal articles black. Pronotum black; tegula pale yellow; propleural flange black, anteriorly yellow marked. Fore and mid legs pale yellow; distal tarsal article of mid leg brownish. Hind coxa black; trochanter black, distally yellow; trochantellus yellow; hind femur basally and distally orange and infuscate; hind tibia black, basally yellow; hind tibial spurs white; hind tarsal segments basally yellow light, distally black, except distal segment entirely black. Metasoma entirely black, except sternite II entirely and sternite III posteriorly, white. Wings hyaline; veins brownishyellow.

Male: Similar to female, but propleural flange entirely black, hind femur basally and distally less infuscate, and hind tibia basally not yellow. Antenna, with 37 flagellomeres; scape and pedicel are entirely black.

Biology: unknown.

Etymology: The species name derives from the Tupy language (Turú = big) with reference to the dimensions of the specimens.

Material: Holotype $q$ (DCBU), Campos do Jordão, São Paulo, Brazil, 27.IX-12.X.2001, Malaise trap, 1900 m, S. A. G. Gomes col. Paratypes (1ㅇ, $2 \hat{} \widehat{A}:$ DCBU): same as holotype.

\section{Aiura miri n. sp.}

Female: Fore wing length $3.5 \mathrm{~mm}$. Head with interocellar distance about 1.0 times orbital-ocelar distance (Fig. 3); mandible with a lamella gradually narrowed and upper tooth slightly longer than lower; temple moderately long; eyes moderately indented opposite antennal sockets; cheek about 0.60 basal mandibular width; antenna with 28 flagellomeres; genal carina joining hypostomal carina.

Mesoscutum uniformily coriaceous, without notaulices; propleura uniformly coriaceous; mesopleuron coriaceous, not rugose in front speculum, lower part of mesopleuron without sternaulus impressed; posterior mesosternal carina complete; scutellum weakly convex, without carinae; metapleuron coriaceous. Propodeum (Fig. 4) coriaceous and posteriorly slightly rugose, 

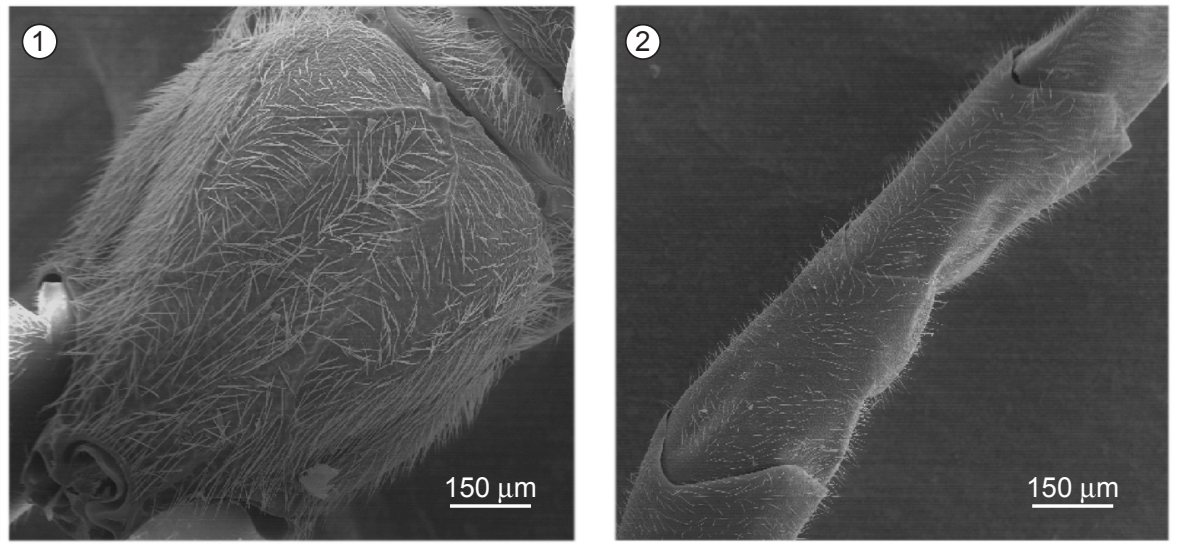

Figs. 1-2 - Aiura turu n. sp. 1, dorsal view of propodeum. 2, dorsal view of tergites incised mid-dorsally.
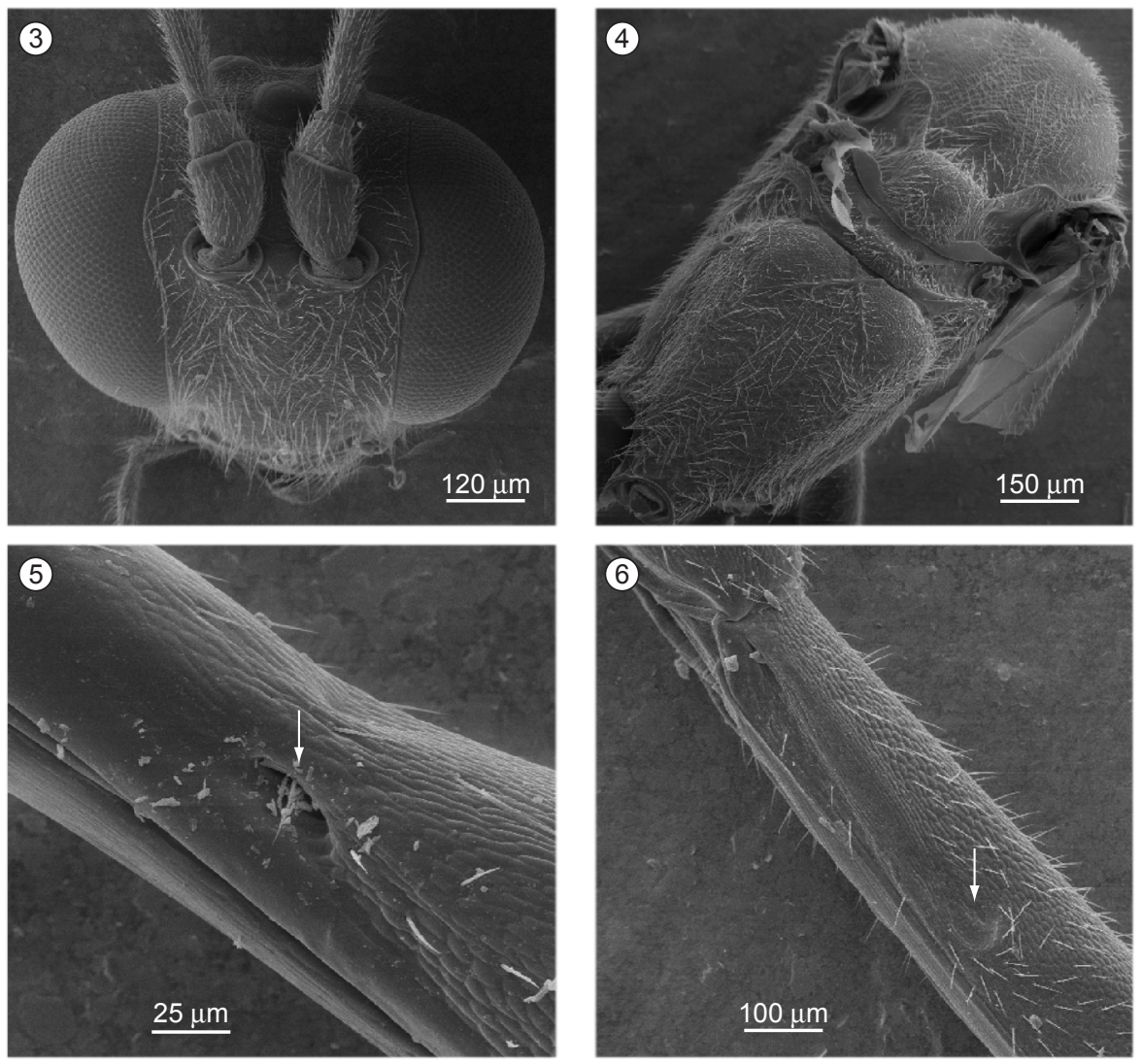

Figs. 3-6 - Aiura miri n. sp. 3, frontal view of head. 4, dorsal view of propodeum. 5, side view of petiole, with glymma indicated. 6, lateral view of petiole, with thyridium indicated.

bearing less dense pubescence; spiracle propodeal circular; propodeal carina obsolescent.

First segment with suture between tergite and sternite ventral, deep glymma in front of spiracle; second tergite long with subcircular thyridium separated from base of tergite by about 4.0-4.5 times its length. Ovipositor stout, strongly up curved, about 1.7 times as long as apical depth of abdomen. 
Black; mouthparts yellow; antenna dark brown. Pronotum black; tegula pale yellow; propleural flange black. Fore and mid legs with coxa; femur and tibia orange; trochanter and trochantellus yellow white; tarsus orange, distal article brown. Hind coxa black; trochanter black, distally yellow light; trochantellus yellow light; hind femur brown, basally and distally slightly infuscate; hind tibia centrally orange and blackish at proximal and distal apices; hind tibial spurs white; hind tarsal segments brown. Metasoma entirely black except sternite II entirely and sternite III posteriorly white. Wings hyaline; veins brownishyellow.

This species differs from A. turu mainly in its body length; propodeal carina and color of antenna, anterior two pairs of legs, hind tibia and hind tarsal segments.

Etymology: The species name derives from the Tupy language (Miri $=$ small) with reference to the dimensions of the specimens.

Male: unknown.

Biology: unknown.

Material: Holotype + (DCBU), Campos do Jordão, São Paulo, Brazil, 27.IX-12.X.2001, Malaise trap, 1800 m, S.A. G. Gomes col. Paratypes
(3ㅇ: DCBU): 1 , , same locality, 27.IX-12.X.2001, Malaise trap, $1200 \mathrm{~m} ; 1$, , same locality, 27.IX12.X.2001, Malaise trap, $1100 \mathrm{~m} ; 1$, , same locality, 23.XI-10.XII.2001, Malaise trap, 1900m, S. A. G. Gomes col..

Acknowledgments - The authors are grateful to CNPq (Conselho Nacional de Desenvolvimento Científico e Tecnológico) for financial support; Silvana A. G. Gomes for collecting the material; Magda V. Yamada who offered valuable suggestions to improve this article, to Alécio A. Pimenta Jr. and the Instituto de Física da Universidade de São Paulo for the Scanning Electronic Microscopy pictures.

\section{REFERENCES}

DESANTIS, L., 1980, Catalogo de los himenopteros brasilenõs de la serie Parasitica, incluyendo Bethyloidea. Edit. Universidade Federal do Paraná. Curitiba, pp. 395.

TOWNES, H. \& TOWNES, M., 1966, A catalogue and reclassification of Neotropic Ichneumonidae. Memoirs of the American Entomological Institute, 8: 1-367.

TOWNES, H., 1969, The genera of Ichneumonidae (Part 1). Memoirs of American Entomological Institute, 11: 1-300.

TOWNES, H., 1970, The genera of Ichneumonidae (Part 3). Memoirs of American Entomological Institute, 13: 1-307.

KUMAGAI, A. F. \& GRAF, V., 2000, Ichneumonidae (Hymenoptera) de áreas urbana e rural de Curitiba, Paraná, Brasil. Acta Biológica Paranaense, 29: 153-168. 